Emry, E.L., et al., 2020, Prominent thermal anomalies in the mantle transition zone beneath the Transantarctic Mountains: Geology, v. 48, https://doi.org/10.1130/G47346.1

Supplemental Material for:

\title{
Prominent thermal anomalies in the mantle transition zone beneath the Transantarctic Mountains
}

Erica L. Emry ${ }^{1,2}$, Andrew A. Nyblade ${ }^{3}$, Alan Horton¹, Samantha E. Hansen², Jordi Julià4, Richard C. Aster ${ }^{5}$, Audrey D. Huerta6 ${ }^{6}$ J. Paul Winberry6, Douglas A. Wiens7, and Terry J. Wilson 8

${ }^{1}$ Earth and Environmental Sciences Department, New Mexico Institute of Mining and Technology, Socorro, New Mexico 87801, USA

${ }^{2}$ Geological Sciences Department, The University of Alabama, Tuscaloosa, Alabama 35487, USA

${ }^{3}$ Geosciences Department, Pennsylvania State University, University Park, Pennsylvania 16802, USA

${ }^{4}$ Departmento de Geofisica, UFRN, Natal, Brazil

${ }^{5}$ Geosciences Department, Colorado State University, Fort Collins, Colorado 80523, USA

${ }^{6}$ Geological Sciences Department, Central Washington University, Ellensburg, Washington 98926, USA

${ }^{7}$ Earth and Planetary Sciences Department, Washington University in St. Louis, St. Louis, Missouri 63112, USA

${ }^{8}$ Geological Sciences Department, Ohio State University, Columbus, Ohio 43210, USA

\section{Contents of this file}

Appendices S1-S2

Figures S1-S8

Captions for Datasets S1-S2

\section{Additional Supporting Information (Files uploaded separately)}

\author{
Datasets S1-S2
}

\section{Introduction}

The contents of this file include an expanded description of the methods and further discussion of the results, particularly pertaining to effects of migrating the receiver functions according to different 3-D velocity models. We include plots of our most conservative and least conservative MTZ thickness estimates (Figure S1), a map of the 410LVL amplitude for our results merged with Emry et al. (2015; Figure S2), a map of mantle transition zone (MTZ) thickness for our results merged with Emry et al. (2015; Figure S3), cartoons demonstrating the effects of different dynamic models on the MTZ phase transitions (Figure S4), and several lower-mantle shear-wave tomographic models, plotted with the same color scale and the same reference model (Figures S5-S8). Additional information for Datasets S1 and S2 are provided at the end of this file. 


\section{Appendix S1: Expanded description of the methods}

\section{S1.1 Description of the Data and PRF processing}

Our receiver function processing follows Emry et al. (2015); here, we describe that process. Data were collected from the Antarctic Polar Earth Observing Network (POLENETANET; Wiens et al., 2007), the Gamburtsev Mountains Seismic Experiment (Wiens and Nyblade, 2007), the Transantarctic Mountains Seismic Experiment (Anandakrishnan et al., 2000), the Transantarctic Mountains Northern Network (Hansen et al., 2015), and several permanent stations in Antarctica (main text, Figure 1). We requested 40 samples-persecond data for all earthquakes occurring at distances of 30-90 from these Antarctic seismometers, using the Standing Order for Data (SOD) software (Owens et al., 2004) to request data windowed from 10 seconds before to 100 seconds after the predicted P-wave arrival. The waveforms were demeaned, detrended, and tapered with a 5\% cosine window, and they were high-pass filtered above $0.05 \mathrm{~Hz}$ to remove long-period noise. The traces were resampled at 20 samples-per-second after first applying a low-pass filter (8 Hz) to avoid signal aliasing. The horizontal components were rotated into the great circle path in order to obtain radial and transverse components. The metadata associated with a few stations reported sensor misorientations, and steps were taken to rotate those stations to the great circle path, accordingly. We used the iterative, time-domain deconvolution process detailed by Ligorría and Ammon (1999), with 500 iterations to deconvolve the vertical component from the radial and transverse components. A Gaussian filter width of 0.5 (corresponding to frequencies less that $\sim 0.24 \mathrm{~Hz}$ ) was used in the deconvolution process.

We checked the quality of the deconvolution by convolving the vertical component with the final radial receiver function (calculated in the previous step) and rejected all receiver functions that had not recovered at least $80 \%$ of the original radial waveform. To check for any residual rotation or orientation problems, we removed any radial receiver functions that had large amplitudes on the corresponding transverse receiver functions. Radial receiver functions with large amplitudes above a 0.12 threshold were removed to check for issues with large amplitude noise on horizontal components in Antarctica (Anthony et al., 2015). Lastly, we visually inspected all remaining receiver functions to identify any noticeable outliers or polarity issues, though significantly fewer receiver functions were removed at this point. As in Emry et al. (2015), significant efforts were 
made to avoid subjectivity at this step; we did not look for indications of peaks where we might expect them.

\section{S1.2 Description of the PRF migration and stacking (1-D model)}

We used the migration and stacking process described by Owens et al. (2000). P and Ps ray times and locations at depth are calculated using the Tau-P Toolkit (Crotwell et al., 1999), assuming the ak-135 1-D velocity model (Kennett et al., 1995). The receiver functions are then (initially) migrated from time to depth with a $5 \mathrm{~km}$ increment down to $800 \mathrm{~km}$. For initial single-station stacks, all Ps piercing points for each station are stacked together at that depth. For subsequent common-conversion point (CCP) stacks (in slight deviation to the Owens et al., 2000 criteria), a set bin radius is chosen for each of the subregions within our study based on how densely distributed the data is in that region; no requirements for a minimum number of PRFs or stations contributing to the stack were imposed in the automated stacking process. However, we did not interpret peaks from any stacks unless a minimum of 50 PRFs contributed to it. We also highlight that all Southern Victoria Land (SVL) and central Transantarctic Mountains (TAMs) stacks were constrained by at least 3 stations at the depths of the 410' and 660' peaks (with the exception of only one stack with two stations constraining the 410' on the very edge of the central TAMs study region). We deviated from the variable bin approach used by Owens et al. (2000) to maintain a more regular and easily reproducible approach to create the PRF stacks.

After each full PRF stack was created according to the above criteria, we utilized a bootstrap resampling approach to create new stacks, replacing $20 \%$ of the individual PRFs contributing to the full stack with a randomly selected PRF from the main stack (Efron and Tibshirani, 1991). As described in the main text, 200 bootstrap resampled stacks were created and 95\% confidence bounds were created from those resampled stacks. If the lower bound confidence amplitudes at the 410' and 660' peaks were not greater than zero, the peak was not interpreted. The depth uncertainty was subsequently identified from the set of resampled stacks by finding the highest amplitude within $\pm 50 \mathrm{~km}$ depth of the original stack peak location. Those 200 peak depths were then used to find the uncertainty as two standard deviations from the original stack peak (see Dataset S1).

While uncertainties in MTZ thickness can be assessed using the bootstrapped resampled stacks, lateral uncertainty is more difficult to estimate as the stack represents a combination of amplitudes from 50-1000+ individual PRFs. Given the employed stacking 
radii in the SVL and central TAMs regions $\left(1.25^{\circ}\right.$ and $1.5^{\circ}$, respectively), the CCP stacks average structure occurring over distances of at least $\sim 220-330 \mathrm{~km}$. Though numerous stacks show evidence for MTZ thinning, we also observe complexity in the 410' in some stacks. Within a central region for both of the MTZ anomalies, the complexity of the PRF decreases to a simpler, single peak (main text, Figure 2); therefore, we suggest the complexity seen in some of the stacks is produced by combining PRFs from both cooler and hotter regions of the MTZ. Base on these observations, we expect that the lateral extent of MTZ thinning is somewhat comparable to around twice the CCP stack radius $(\sim 200-500$ $\mathrm{km}$ ). However, another aspect to consider is that each individual PRF will also sample some volume around it (the Fresnel Zone), which is dependent upon the frequency of the PRF (e.g., Bina, 2003). The lateral extent of the MTZ anomalies could be further interrogated by stacking several PRF frequencies and multiple bin radii.

\section{S1.3 Description of the 3-D tomographic correction process}

The 3-D migration correction codes were originally written by Owens et al. (2000) for use beneath the East African Rift System. We updated the codes to better exploit increased memory resources on newer computers. For the 1-D tomographic model, we initially calculated the location and timing of $\mathrm{P}$ and Ps rays at $5 \mathrm{~km}$ depth increments. The tomographic correction recalculates the timing of the $\mathrm{P}$ and $\mathrm{Ps}$ rays at each depth increment, taking into account how the assumed 3-D absolute (or relative) velocity model deviates from the originally assumed 1-D model (ak-135; Kennett et al., 1995). These corrected travel-time tables are then used to migrate each individual PRF prior to restacking according to the procedure described above for the CCP stacks.

\section{Appendix S2: Effects of the 3-D velocity tomography corrections}

\section{S2.1 Description of assumed tomographic models}

We investigated the MTZ using three independent tomographic models to correct the migrated receiver functions: the GyPSuM global model (Simmons et al., 2010), the ANT20 Antarctic model (Lloyd et al., 2019), and the relative P- and S-wave Victoria Land models of Brenn et al. (2017). All tomographic models were resampled at $5 \mathrm{~km}$ discretization, and the GyPSuM and Brenn et al. (2017) models were overlain with the An et al. (2015) crustal model at shallow depths. The starting crustal model for ANT-20 (Lloyd et al., 2019) was based on crustal thicknesses from An et al. (2015) and velocities from 
CRUST1.0 (Laske et al., 2013). The models were chosen based on the availability of both Pand S-wave velocities and appropriate resolution in the TAMs region. The methods used to invert for the tomographic models are distinctly different; therefore, the range in absolute peak depth results and MTZ thicknesses can allow us to also understand the uncertainties that arise from assumptions of different velocity models. However, because the resolutions of these models are not easily quantifiable, we do not attempt to strictly interpret absolute peak depths. Below, we provide a general overview of the assumed 3-D tomography models.

GyPSuM is a global model of absolute P- and S-wave velocities and density resulting from a joint inversion constrained by travel-times of many teleseismic $\mathrm{P}$ and $\mathrm{S}$ phases, gravity, plate velocities, dynamic topography, core-mantle boundary ellipticity, and mineral physics (Simmons et al., 2010). Since we cannot quantify the relative uncertainties in $P$ and $S$ wave velocities within different parts of the model throughout Antarctica, we assume that the model is equally well-resolved everywhere. We utilized GyPSuM to migrate our PRFs beneath both the SVL and central TAMs regions.

The Brenn et al. (2017) model is a relative body-wave tomography model created using the methods of Zhao et al. (1994); such models tend to have excellent lateral resolution over a small region but may have resolution challenges in the vertical direction and do not constrain absolute seismic velocities. As such, we take the percent deviations in Brenn et al. (2017) relative to the ak135 1-D average model, recognizing that a 'true' average 1-D model for the region is different. This means that the 410' and 660' peaks cannot be assumed to have the true absolute depths. We used the Brenn et al. (2017) model to migrate our PRFs in the SVL region; however, the model does not extend further south and is therefore not utilized in the central TAMs.

ANT-20 was created using an adjoint, full-waveform inversion method (Lloyd et al., 2019). The model is a continent-scale model, extending out to the mid-ocean ridges encircling Antarctica. The resulting model provides absolute P- and S-wave velocities for our study region. Similar to the GyPSuM model (Simmons et al., 2010), we cannot quantify the relative resolutions of the $\mathrm{P}$ - and S-wave structures within different parts of the model and therefore assume that both P- and S-waves are equally well-resolved everywhere. We utilize ANT-20 to migrate our PRFs beneath both SVL and the central TAMs. 


\section{S2.2 3-D Tomographic Corrections, MTZ thicknesses, and absolute peak depths}

As discussed in Emry et al. (2015) for a 1-D model, if the Vp/Vs ratio increases solely within the upper mantle (i.e., a velocity anomaly is only within the upper mantle), then both the 410' and 660' peaks will be raised to shallower depths and the MTZ thickness will remain the same. However, if the Vp/Vs ratio also increases within the MTZ, then both peaks raise, but the 660' peak raises more, and the MTZ thickness decreases. However, a strong lateral velocity model variation at the boundary of East and West Antarctica further complicates the simple relationship described above.

We expect these lateral variations to be more significant at the boundary between West and East Antarctica; however, we also note that the sharpness of that boundary varies depending on the resolution of the assumed velocity model. In this paper, PRF stacks are constructed using all individual PRFs that are located within a certain bin radius beneath a specified latitude and longitude. Depending on the station and earthquake distribution, as well as the subsequent ray path locations at each $5 \mathrm{~km}$ depth increment, the set of PRFs that are binned together at $410 \mathrm{~km}$ depth may be very different than the set binned together at $660 \mathrm{~km}$ depth. It is possible that individual PRFs may also come from different back-azimuthal directions at different depths, so the sense of the overall tomographic correction (fast versus slow) could be different for different stack depths. Below, we discuss our observations of changes in the MTZ thickness and the 410' and 660' absolute peak depths, depending on the assumed 3-D tomographic model.

\section{S2.2.1 Mantle Transition Zone Thickness}

In Dataset S1, Sheet 6, we indicate the spread in MTZ thicknesses for all four (one 1D and three 3-D) tomographic models for the central TAMs and the SVL anomalies. We find that the average spread for MTZ thickness is $\sim 4 \mathrm{~km}$ in the central TAMs, and the average spread for MTZ thickness is $\sim 6 \mathrm{~km}$ in SVL. The standard deviation for the spread in MTZ thicknesses is $\sim 3 \mathrm{~km}$ for the central TAMs and $\sim 9 \mathrm{~km}$ for the SVL region, making it clear that various velocity models make a bigger impact on the results from SVL. This is very likely due to the observed complexity in the 410 ' beneath SVL.

\section{S2.2.1 410' and 660' Absolute Peak Depths}

In Dataset S1, Sheet 6, we also analyze the average spread between all four models for the absolute 410' and 660' peak depths. Beneath the central TAMs, the average spread 
between the four models is $\sim 2.5 \mathrm{~km}$ for the $410^{\prime}$ and $\sim 3.5 \mathrm{~km}$ for the $660^{\prime}$. In SVL, the average spread is $\sim 6 \mathrm{~km}$ for the $410^{\prime}$ and $\sim 4 \mathrm{~km}$ for the $660^{\prime}$. In addition, we analyzed the change in the 410' and the 660' peak depths for each of the assumed 3-D tomographic models in comparison to the initial, 1-D absolute peak depth. Where the difference between the 1-D peak depth and the 3-D peak depth is positive, the 3-D tomographic model has raised (shallowed) the peak; where this quantity is negative, the 3-D tomographic model has deepened the peak.

In the central TAMs, the average change in the 410' is $\sim-2 \mathrm{~km}$ for the GyPSuM model and $\sim-1.5 \mathrm{~km}$ for the ANT-20 model, meaning that the assumption of these models deepens the $410^{\prime}$ on average by $\sim 2 \mathrm{~km}$. For the 660', the GyPSuM model deepens the 660' on average by $\sim 2 \mathrm{~km}$, while the ANT-20 model raises the 660' by $\sim 1 \mathrm{~km}$ on average. This means that on average, the GyPSuM model has similar MTZ thickness, and the ANT-20 model thins the MTZ further by $\sim 3 \mathrm{~km}$.

Beneath SVL, the average change in the 410' using GyPSuM is $~ 3.5 \mathrm{~km}$ deeper, Brenn et al. (2017) is $\sim 3 \mathrm{~km}$ deeper, and ANT-20 results in $\sim 0 \mathrm{~km}$ change. At the 660 ', the average change is $\sim 2 \mathrm{~km}$ deeper for GyPSuM, $\sim 2 \mathrm{~km}$ deeper for Brenn et al. (2017), and $\sim 1$ km shallower for the ANT-20 model. For all of these models, this means the MTZ thins on average by $\sim 1-1.5 \mathrm{~km}$. Despite the small average changes in this sub-region, we observed some changes as large as $\sim 40-45 \mathrm{~km}$ for the $410^{\prime}$, though variations were more often in the \pm 0 -10 km range. Again, this is likely due to the complexity observed in the 410' causing the deeper peak to become higher amplitude when migrated with the 3-D tomographic models. 

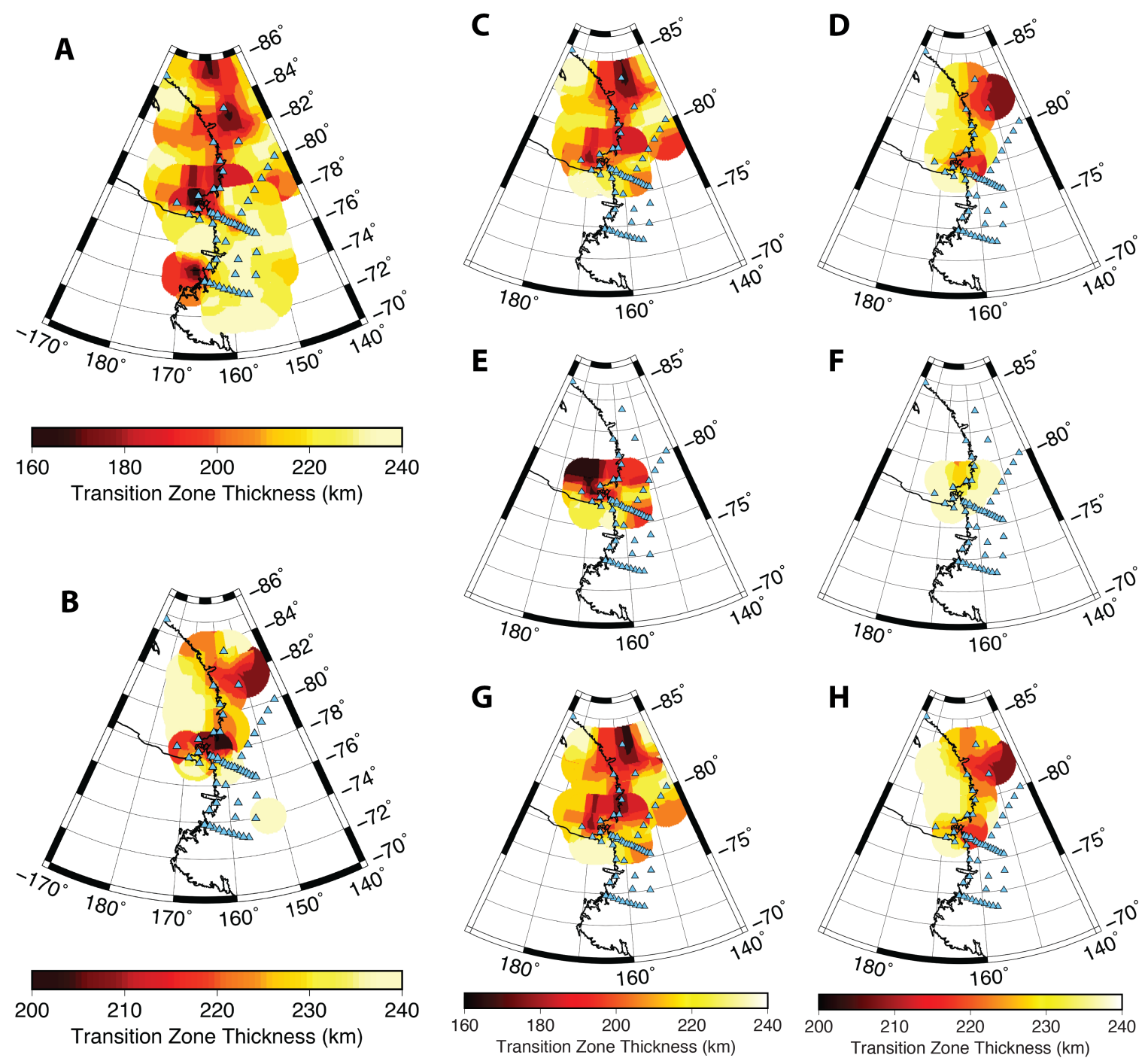

Figure S1: A and B) "Hot" and "Cold" MTZ scenarios applying the 1-D ak135 model (Kennett et al., 1995). The other panels are the same, applying the GyPSuM model (C and D; Simmons et al., 2010), the Brenn et al. (2017) model (E and F), and the Lloyd et al. (2019) ANT-20 model (G and H). "Hot" scenarios (center column) show the thinnest MTZ estimates after combining the depth uncertainties for the MTZ discontinuities (i.e.., MTZ thickness - (410 km uncertainty + $660 \mathrm{~km}$ uncertainty)). "Cold" scenarios (right column) show the thickest MTZ estimates, also after combining the depth uncertainties (i.e., MTZ thickness $+(410$ uncertainty +660 uncertainty $)$ ). 


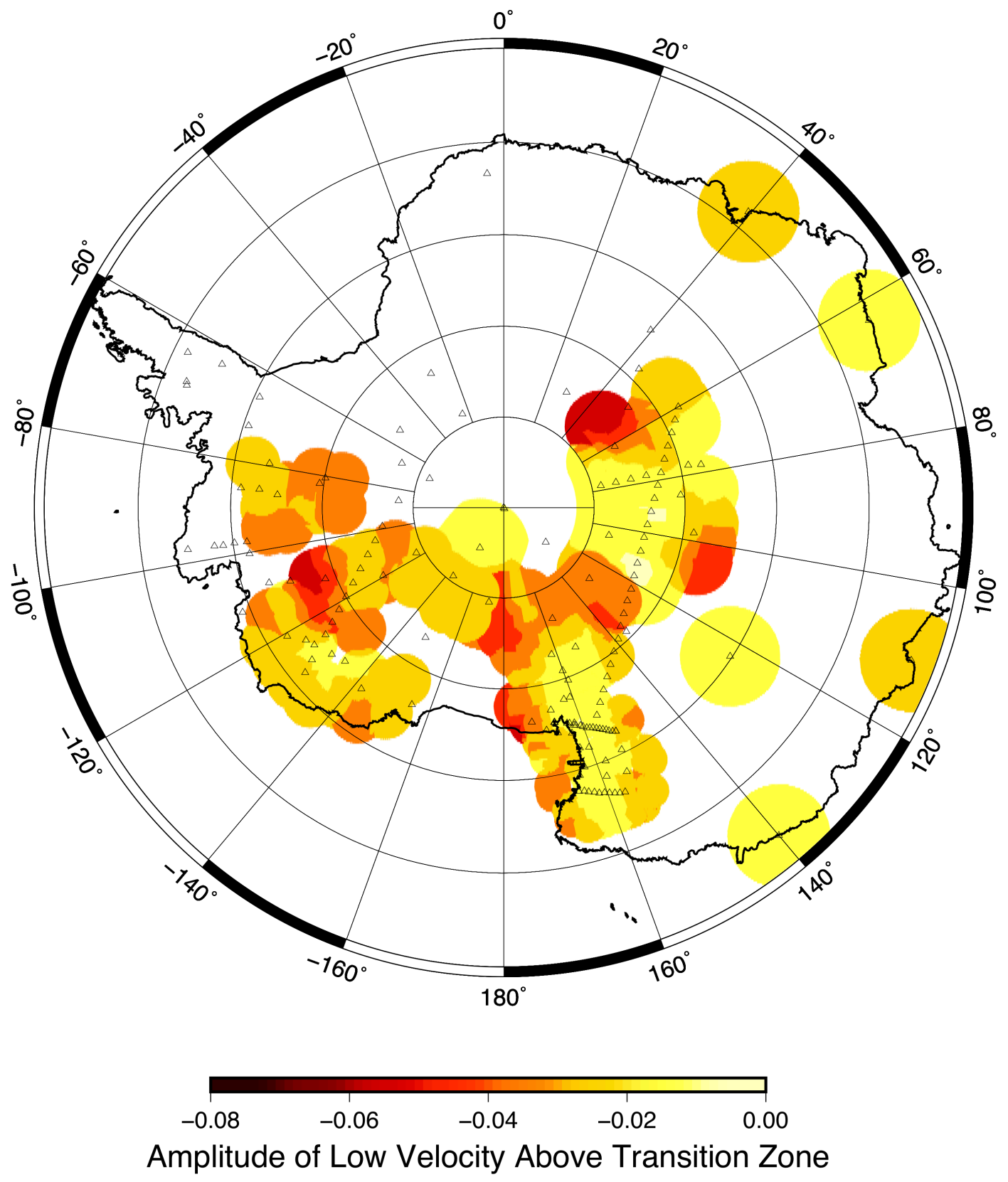

Figure S2: 410-LVL (low velocity layer) amplitude above the MTZ for results migrated using the ak135 1-D global velocity model (Kennett et al., 1995), plotted alongside results from West Antarctica and Marie Byrd Land (MBL; Emry et al., 2015), which were stacked using the same 1-D velocity model. Isolated seismic stations show MTZ thickness from single-station stacks; stations are plotted as open triangles. $2.0^{\circ}$ radius CCP stacks are plotted in East Antarctica (longitude $<135^{\circ}$ ), $1.5^{\circ}$ radius CCP stacks are plotted along the central TAMs region (south of $79^{\circ} \mathrm{S}$ ), and $1.0^{\circ}$ radius CCP stacks are plotted within Victoria Land (north of $79^{\circ} \mathrm{S}$ ). Results from Emry et al. (2015) show $1.5^{\circ}$ radius CCP stacks. The results suggest that the $410-\mathrm{LVL}$ is most prominent beneath MBL and the central TAMs regions. 


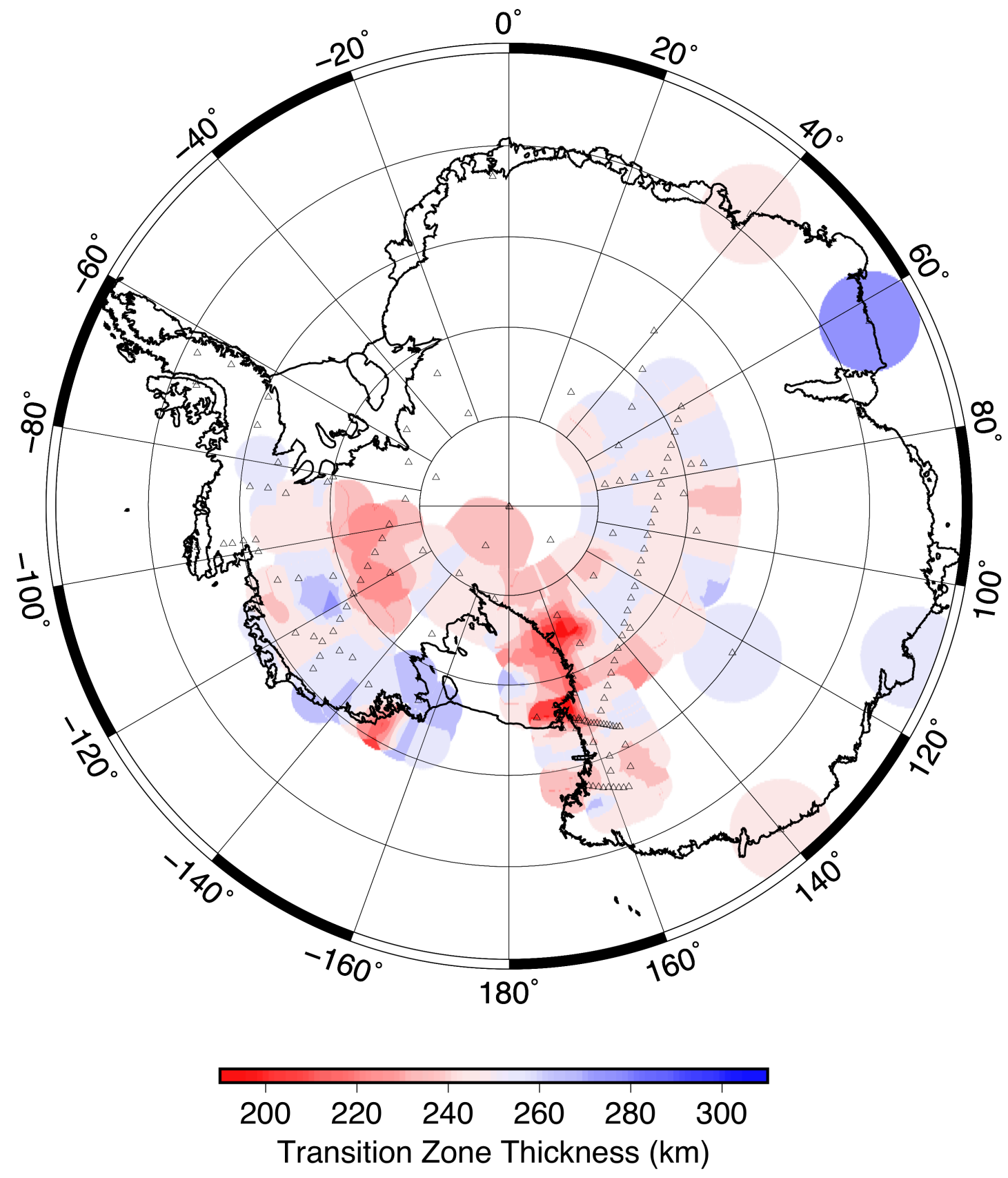

Figure S3: MTZ thickness estimates from the current study, migrated using a 1-D global average model (Kennett et al., 1995), plotted alongside prior results from West Antarctica and Marie Byrd Land (Emry et al., 2015), which were also stacked using the same 1-D velocity model. Isolated seismic stations show MTZ thickness from single-station stacks; stations are plotted as open triangles. 2.0 $0^{\circ}$ radius CCP stacks are plotted in East Antarctica (longitude $<135^{\circ}$ ), $1.5^{\circ}$ radius CCP stacks are plotted along the central TAMs region (south of $79^{\circ} \mathrm{S}$ ), and $1.0^{\circ}$ radius CCP stacks are plotted within Victoria Land (north of $79^{\circ} \mathrm{S}$ ). Results from Emry et al. (2015) show $1.5^{\circ}$ radius CCP stacks. 


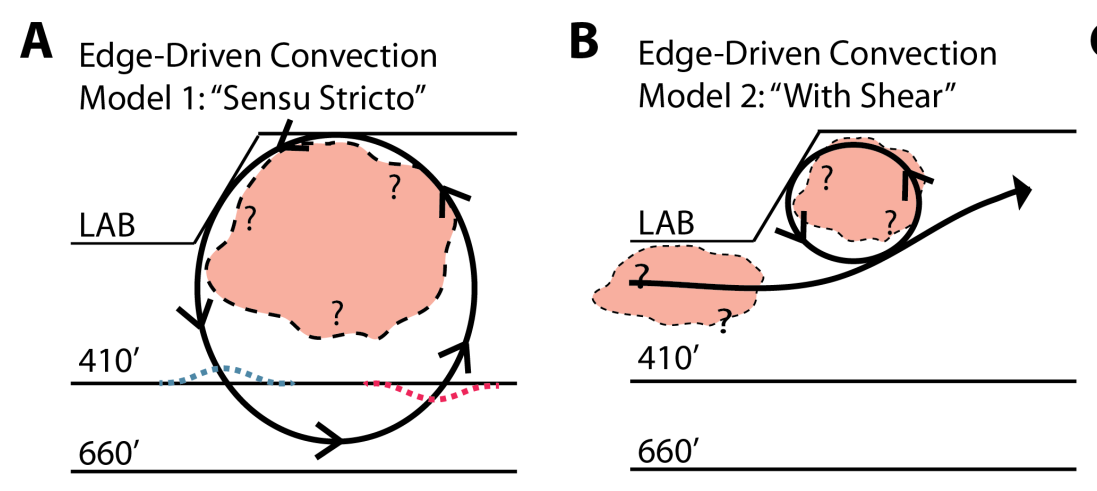

C Mantle Plume Model
Model 3: "Ponded Mantle Plume"

Figure S4: Cartoons illustrating three possible scenarios of mantle dynamics beneath the TAMs, at the edge of the thick East Antarctic and thin West Antarctic lithosphere. A) The edge-driven convection (EDC) sensu stricto model (Kasilaniemi and van Hunen, 2014) and our inferred effects on the depth of the 410' phase transition. The blue dashed line shows a raised 410' beneath predicted cold down-wellings at the edge of the lithosphere, and the red dashed line shows a depressed 410' beneath the predicted warm upwelling at large distance $(>300 \mathrm{~km})$ from the edge of the lithosphere. B) The EDC with shear model (Kasilaniemi and van Hunen, 2014). In this model, asthenosphere beneath the thick continental lithosphere would heat up due to continental insulation and would flow beneath West Antarctica; however, we do not expect this to produce an effect on the MTZ phase transitions. C) Model showing a low-velocity, uppermost lower mantle and a lowvelocity, upper mantle connected by a through-going mantle plume. In this model, we would expect to see a depressed 410' and a raised 660' (red dashed lines) that results in MTZ thinning. We note that because of uncertainties in upper mantle and MTZ velocity structure, MTZ thinning may be a more robust observation to base our interpretations on compared to absolute peak depths. 


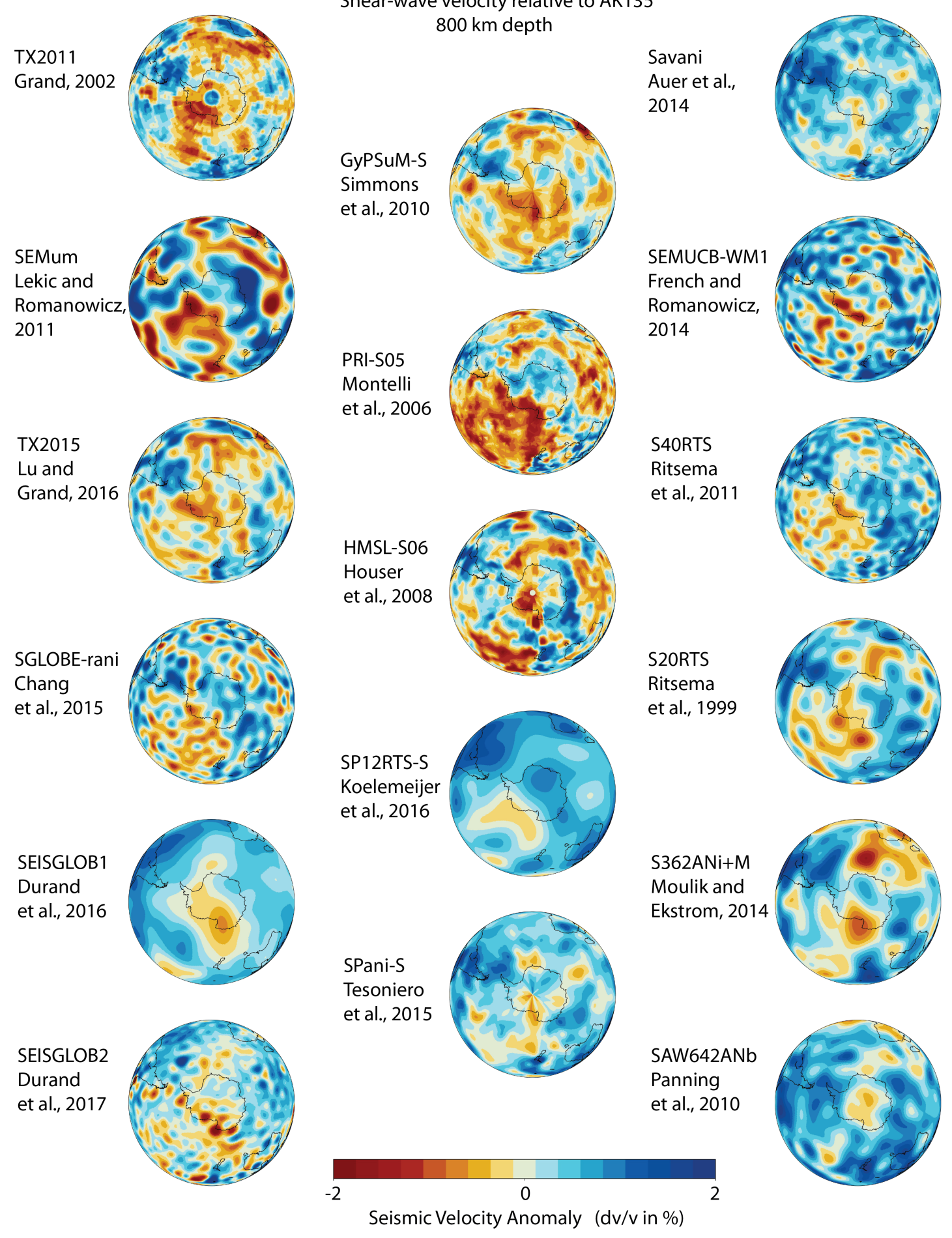

Figure S5: Global dVs tomographic models ( $\pm 2 \%$ relative to ak135; Kennett et al., 1995) at $800 \mathrm{~km}$ depth. Many of the models suggest low-velocities in the shallow lower mantle beneath the TAMs and East Antarctica; other models limit low-velocity features to beneath West Antarctica. These models allow for the possibility that a lower mantle upwelling has stalled at the base of the MTZ and may provide a source for mantle plumes that rise through the MTZ. All models were plotted in reference to the same velocity model using SubMachine tomography tools (https://www.earth.ox.ac.uk/ smachine/cgi/index.php). 


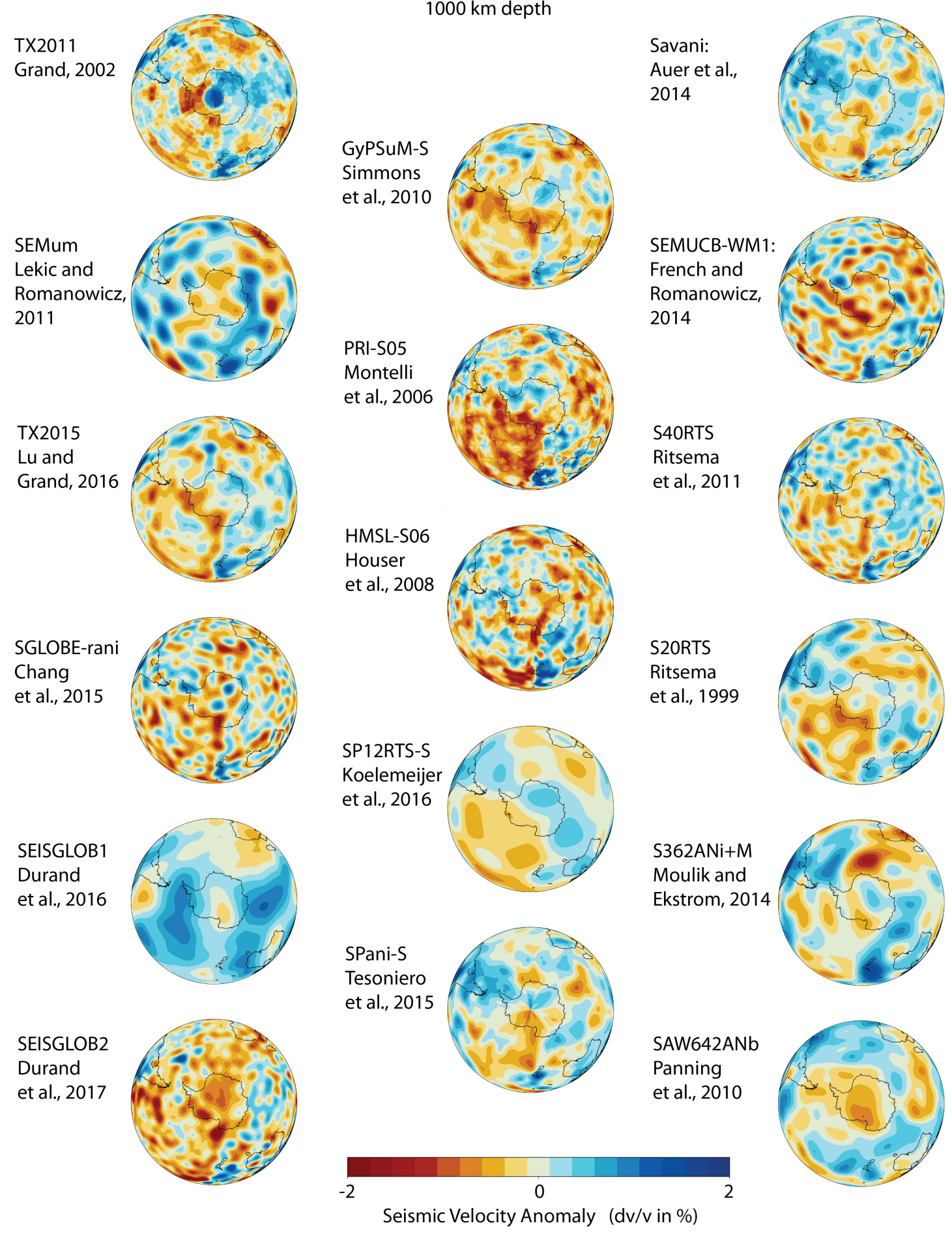

Figure S6: Same as Figure S5 but now at 1,000 km depth. Again, many of the models suggest low-velocities in the shallow lower mantle beneath the TAMs and East Antarctica; other models limit low-velocity features to beneath West Antarctica. These models allow for the possibility that a lower mantle upwelling has stalled at the base of the MTZ and may provide a source for mantle plumes that rise through the MTZ. All models were plotted in reference to the same velocity model using SubMachine tomography tools (https://www.earth.ox.ac.uk/ smachine/cgi/index.php). 

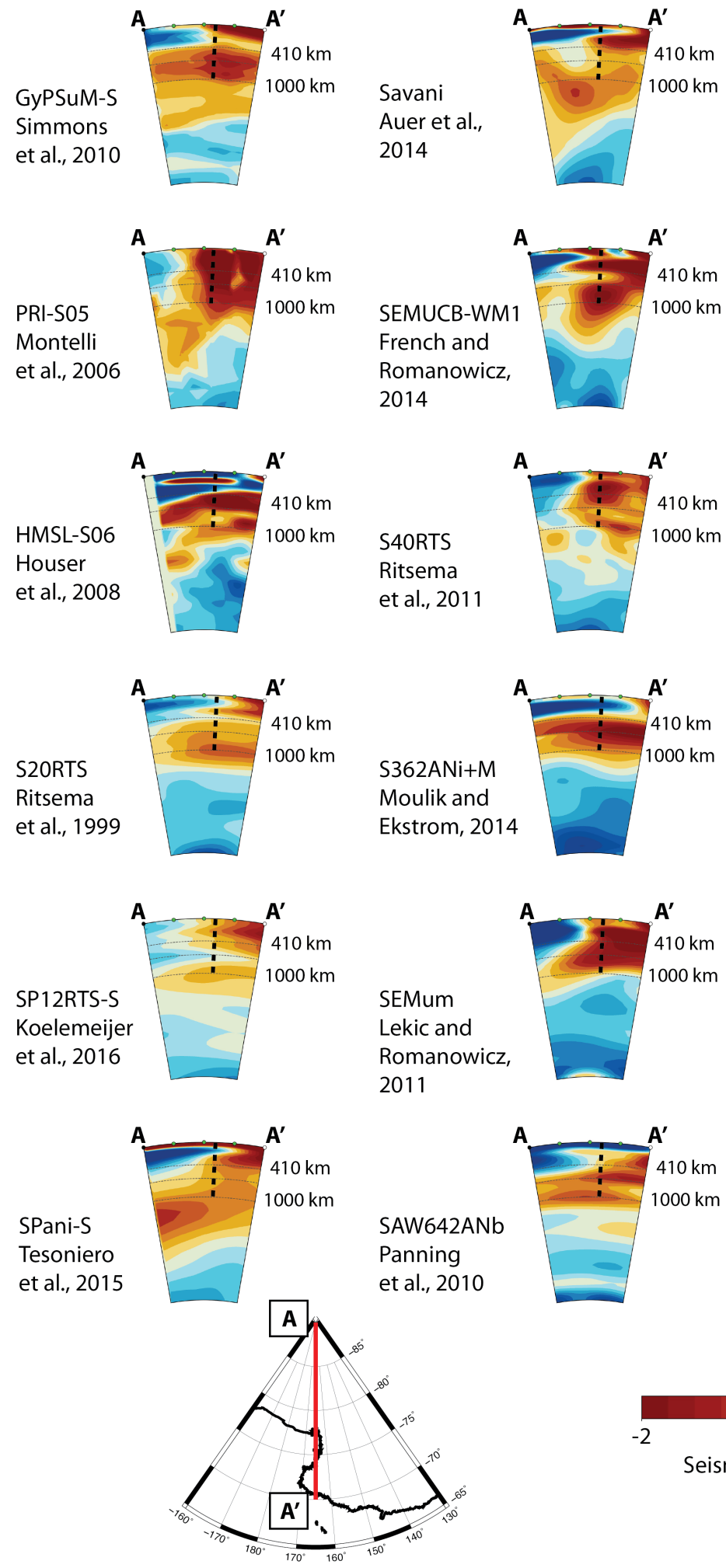

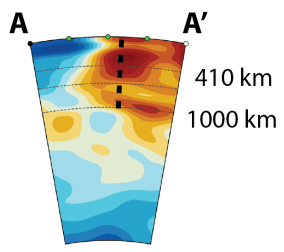

S40RTS

Ritsema

et al., 2011

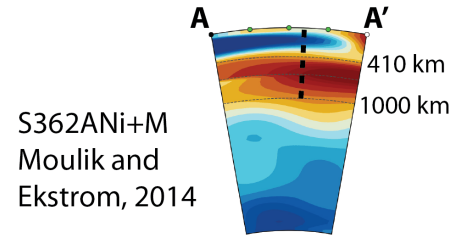

SEMum

Lekic and

Romanowicz,

2011
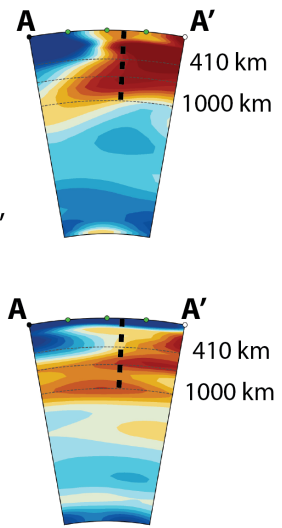

Grand, 2002
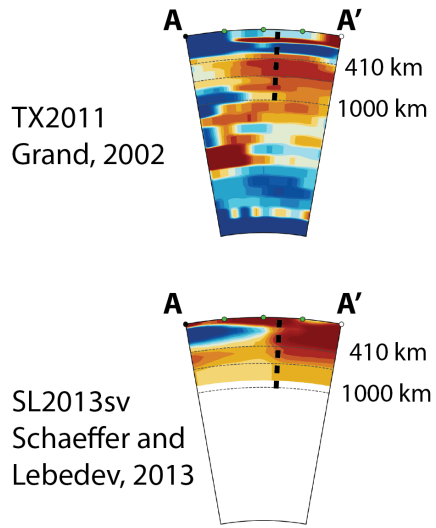

TX2015

Lu and

Grand, 2016
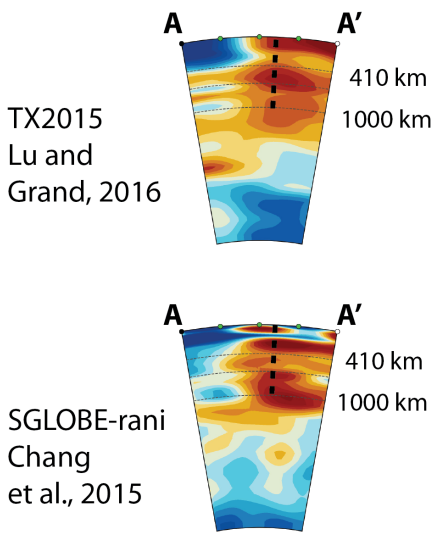

SEISGLOB1

Durand

et al., 2016

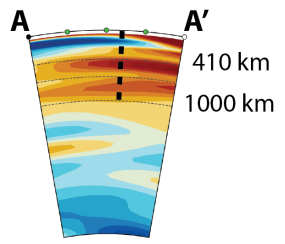

SEISGLOB2

Durand

et al., 2017

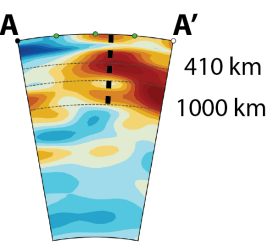

Figure S7: Seismic tomography cross-sections through the mantle along longitude $165^{\circ} \mathrm{E}$. In each model slice, the South Pole is positioned along the left edge, and the right edge is the northern TAMs (latitude $70^{\circ} \mathrm{S}$ ). Many of the models suggest low-velocities in the MTZ and/or the top of the lower mantle beneath Ross Island (shown as vertical dashed, black lines). All models were plotted in reference to the same velocity model using SubMachine tomography tools (https://www.earth.ox.ac.uk/ smachine/cgi/index.php). 

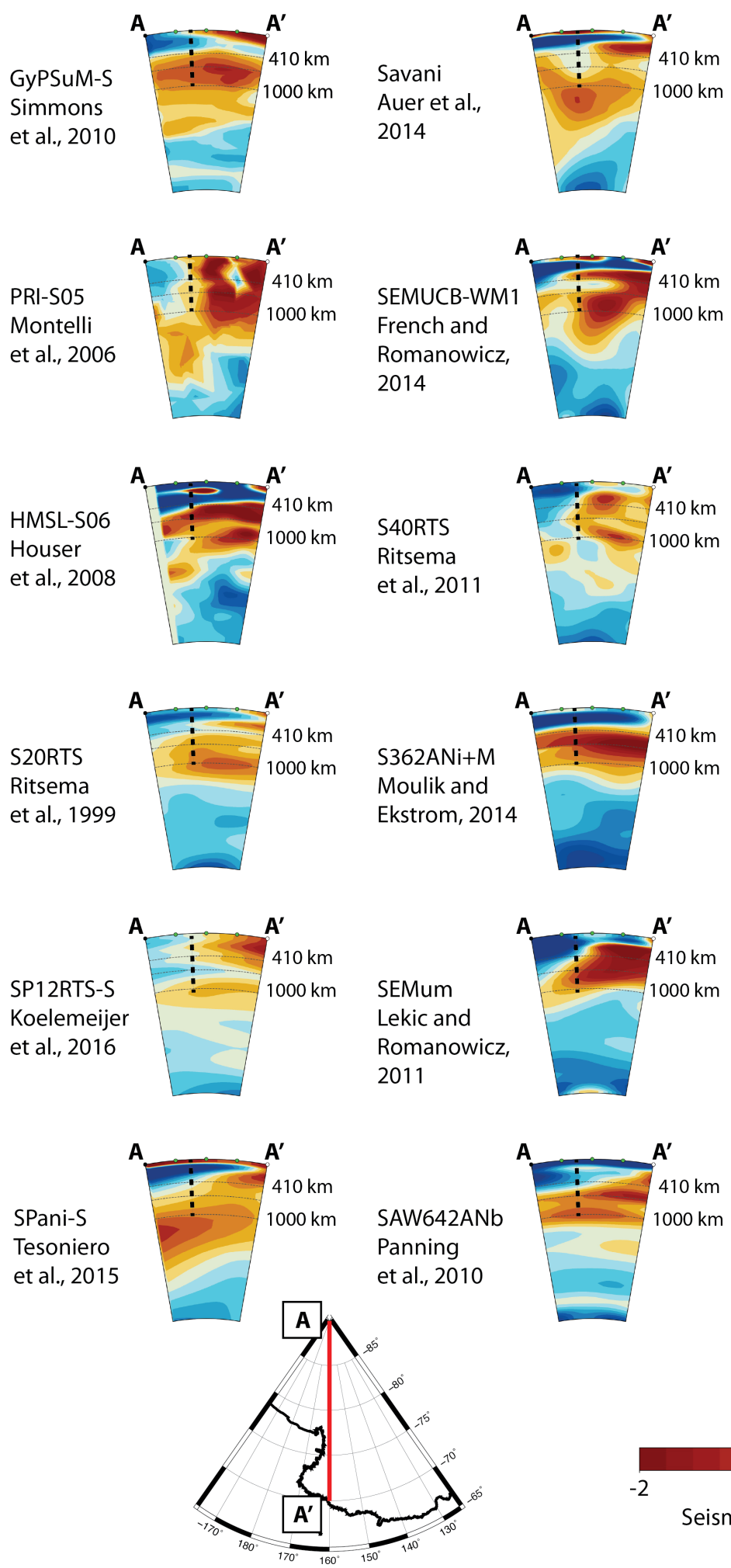

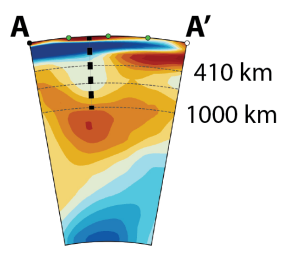

TX2011

Grand, 2002
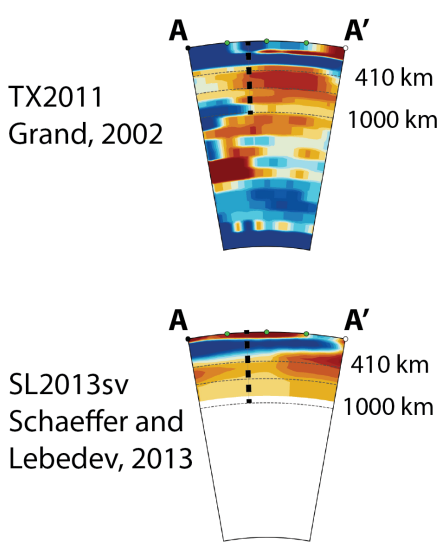

TX2015

Lu and

Grand, 2016
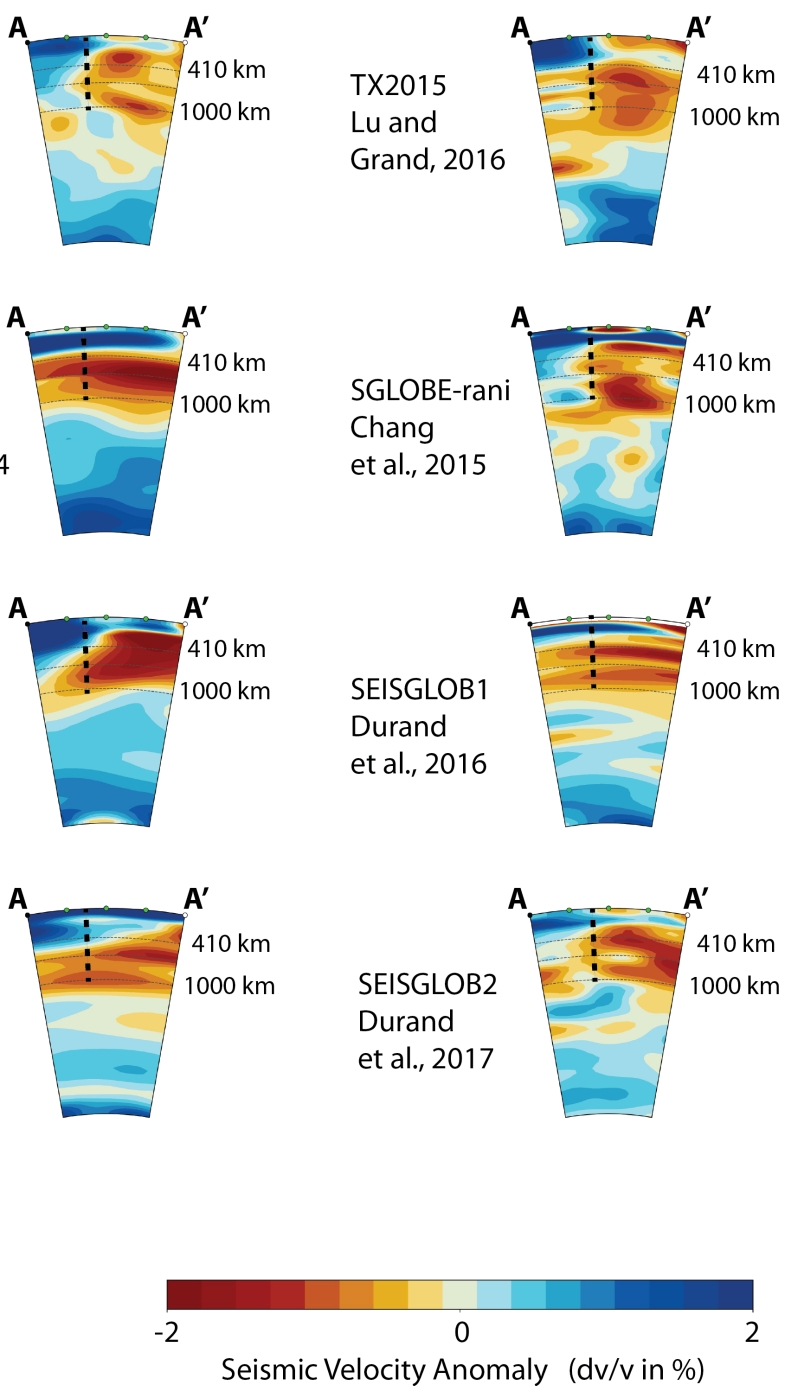

Figure S8: Seismic tomography cross-sections through the mantle along longitude $160^{\circ} \mathrm{E}$. In each model slice, the South Pole is positioned along the left edge, and the right edge is the northern TAMs (latitude $70^{\circ} \mathrm{S}$ ). Many of the models suggest low-velocities at the top of the lower mantle beneath the central TAMs and several indicate low-velocities also in the MTZ (vertical dashed black lines). All models were plotted in reference to the same velocity model using the SubMachine seismic tomography visualization tools (https://www.earth.ox.ac.uk/ smachine/cgi/index.php). 


\section{Dataset S1 Caption:}

Dataset file name is Emry_etal_G47346R_DatasetS1.xlsx

File is separated into several sheets:

Sheet 1: Single-station stacks, migrated with ak135 (Kennett et al., 1995)

Column A: Network and station code, separated by a period

Column B: Number of quality PRFs in the stack

Column C: Depth (km) of the 410'-low velocity layer (LVL), a negative peak above the MTZ that may be an indicator of MTZ hydration or anomalous composition

Column D: Amplitude of the 410'-LVL peak

Column E: Depth (km) of the 410' discontinuity

Column F: Depth uncertainty $(\mathrm{km})$ of the $410^{\prime}$ discontinuity peak, obtained by bootstrap resampling

Column G: Amplitude of the 410' discontinuity peak

Column H: Depth (km) of the 660' discontinuity

Column I: Depth (km) uncertainty of the 660' discontinuity peak

Column J: Amplitude of the 660' discontinuity peak

Column K: MTZ thickness (km)

Column L: Combined MTZ depth uncertainty (km)

Column M: Were the station PRFs used in the CCP stack (Y or N); if not used, something looked amiss with the calculated PRFs (noisy, poor amplitude, etc.)

Sheets 2-5: Common-conversion point (CCP) stacks

Each sheet (2-5) is separated into the following columns:

Column A: Center latitude $\left({ }^{\circ} \mathrm{N}\right)$ of the stacking bin

Column B: Center longitude $\left({ }^{\circ} \mathrm{E}\right)$ of the stacking bin

Column C: Stacking bin radius $\left({ }^{\circ}\right)$

Column D: Is the "cold" MTZ thickness (most conservative) estimate $<240 \mathrm{~km}$ ? (Y or N)

Column E: Depth (km) of the 410'-LVL

Column F: Amplitude of the 410'-LVL peak

Column G: Depth (km) of the 410' discontinuity

Column H: Depth uncertainty $(\mathrm{km})$ of the 410 ' discontinuity

Column I: Amplitude of the 410' discontinuity

Column J: Number of PRFs contributing to the stack at the 410' peak depth

Column K: Number seismic stations contributing to the stack at the 410' peak depth

Column L: Depth (km) of the 660' discontinuity

Column M: Depth uncertainty $(\mathrm{km})$ of the $660^{\prime}$ discontinuity

Column N: Amplitude of the 660' discontinuity

Column 0: Number of PRFs contributing to the stack at the 660' peak depth

Column P: Number seismic stations contributing to the stack at the 660' peak depth

Column Q: MTZ thickness (km)

Column R: Combined MTZ depth uncertainty $(\mathrm{km})$

Column S: "Hot" MTZ thickness (least conservative) after subtracting the combined uncertainty (col. R) from the MTZ thickness (col. Q)

Column T: "Cold" MTZ thickness (most conservative) after adding the combined uncertainty (col. R) to the MTZ thickness (col. Q)

Column U: Robust Detection uncertainty (if T column is $<250 \mathrm{~km}$ ), last row beneath each group shows the average robust detection uncertainty 
Sheet 2: CCP stacks, migrated with ak135 (Kennett et al., 1995)

Sheet 2 is separated into four regional groups, with columns described as above:

Victoria Land, stacked with a $1.0^{\circ}$ radius

Southern Victoria Land (SVL), stacked with a $1.25^{\circ}$ radius

Central TAMs, stacked with a $1.5^{\circ}$ radius

East Antarctica, stacked with a $2.0^{\circ}$ radius

Sheet 3: CCP stacks, migrated with GyPSuM (Simmons et al., 2010)

Sheet 3 is separated into two regional groups, with columns described as above:

Central TAMs, stacked with a $1.5^{\circ}$ radius

SVL, stacked with a $1.25^{\circ}$ radius

Sheet 4: CCP stacks, migrated with model from Brenn et al. (2017)

Sheet 4 shows one regional group, with columns described as above:

SVL, stacked with a $1.25^{\circ}$ radius

Sheet 5: CCP stacks, migrated with ANT-20 (Lloyd et al., 2019)

Sheet 5 is separated into two regional groups, with columns described as above:

Central TAMs, stacked with a $1.5^{\circ}$ radius

SVL, stacked with a $1.25^{\circ}$ radius

Sheet 6: Comparison between CCP results from different velocity models

Sheet 6 is separated into two regional groups (as in Sheets 3 and 5), with the following columns:

Column A: Central latitude $\left({ }^{\circ} \mathrm{N}\right)$ of the stacking bin

Column B: Central longitude $\left({ }^{\circ} \mathrm{E}\right)$ of the stacking bin

Column C: Stacking bin radius $\left({ }^{\circ}\right)$

Column D: Is the average (mean) MTZ thickness $<=225 \mathrm{~km}$ ? (Y or N)

Column E: Depth (km) of the 410' discontinuity, ak135 model (Kennett et al., 1995)

Column F: Depth (km) of the 410' discontinuity, GyPSuM model (Simmons et al., 2010)

Column G: Depth (km) of the 410' discontinuity, Brenn et al. (2017) model

Column H: Depth (km) of the 410' discontinuity, ANT-20 model (Lloyd et al., 2019)

Column I: Spread of the 410' discontinuity (km) across models

Column J: Depth (km) of the 660' discontinuity, ak135 model (Kennett et al., 1995)

Column K: Depth (km) of the 660' discontinuity, GyPSuM model (Simmons et al., 2010)

Column L: Depth (km) of the 660' discontinuity, Brenn et al. (2017) model

Column M: Depth (km) of the 660' discontinuity, ANT-20 model (Lloyd et al., 2019)

Column N: Spread of the 660' discontinuity (km) across models

Column 0: MTZ thickness (km), ak135 model (Kennett et al., 1995)

Column P: MTZ thickness uncertainty (km), ak135 model (Kennett et al., 1995)

Column Q: MTZ thickness (km), GyPSuM model (Simmons et al., 2010)

Column R: MTZ thickness uncertainty (km), GyPSuM model (Simmons et al., 2010)

Column S: MTZ thickness (km), Brenn et al. (2017) model

Column T: MTZ thickness uncertainty (km), Brenn et al. (2017) model

Column U: MTZ thickness (km), ANT-20 model (Lloyd et al., 2019)

Column V: MTZ thickness uncertainty (km), ANT-20model (Lloyd et al., 2019)

Column W: Spread of the MTZ thickness $(\mathrm{km})$ across models

Column X: Spread of the MTZ thickness uncertainties (km) across models

Column Y: Average (mean) MTZ thickness (km) 
Column Z: Mean MTZ thickness uncertainty (km)

Column AA: Mean "Hot" MTZ thickness (least conservative) after subtracting the mean MTZ thickness uncertainty (col. Z) from the mean MTZ thickness (col. Y)

Column AA: Mean "Cold" MTZ thickness (most conservative) after adding the mean MTZ thickness uncertainty (col. Z) to the mean MTZ thickness (col. Y)

Column AD: Difference in 410' peak depth (km) between GyPSuM (Simmons et al., 2010) and 1-D model (Kennett et al., 1995). Yellow colors denote a positive change (shallower using the 3-D model); orange denotes a negative change.

Column AE: Difference in 410' peak depth (km) between Brenn et al. (2017) and 1-D model (Kennett et al., 1995). Yellow colors denote a positive change (shallower using the 3-D model); orange denotes a negative change.

Column AF: Difference in 410' peak depth (km) between ANT-20 (Lloyd et al. 2019) and 1-D model (Kennett et al., 1995). Yellow colors denote a positive change (shallower using the 3-D model); orange denotes a negative change.

Column AG: Difference in 660' peak depth (km) between GyPSuM (Simmons et al., 2010) and 1-D model (Kennett et al., 1995). Yellow colors denote a positive change (shallower using the 3-D model); orange denotes a negative change.

Column AH: Difference in 660' peak depth (km) between Brenn et al. (2017) and 1-D model (Kennett et al., 1995). Yellow colors denote a positive change (shallower using the 3-D model); orange denotes a negative change.

Column AI: Difference in 660' peak depth (km) between ANT-20 (Lloyd et al., 2019) and 1-D model (Kennett et al., 1995). Yellow colors denote a positive change (shallower using the 3-D model); orange denotes a negative change.

\section{Dataset S2 Caption:}

Dataset file name is Emry_etal_G47346R_DatasetS2.xlsx

File is separated into two geographic groups: "Central Transantarctics" (top, corresponding to region B in Figure 2) and "Southern Victoria Land" (bottom, corresponding to region $\mathrm{C}$ in Figure 2).

Calculations were performed using the following equation:

$$
\delta z=Z_{\text {avg }}+\delta T \times \frac{d z}{d P} \times\left[\left(\frac{d P}{d T}\right)_{660}-\left(\frac{d P}{d T}\right)_{410}\right]
$$

with $\left(\frac{d P}{d T}\right)_{410}=3.0 \mathrm{MPa} /{ }^{\circ} \mathrm{K},\left(\frac{d P}{d T}\right)_{660}=-2.6 \mathrm{MPa} /{ }^{\circ} \mathrm{K}, \frac{d P}{d z}=35 \mathrm{MPa} / \mathrm{km}$, and $\left(\mathrm{Z}_{\mathrm{avg}}\right)=250$ or $242 \mathrm{~km}$ average MTZ thickness (Akaogi and Ito, 1993; Bina and Hellfrich, 1994; Katsura et al., 2003; Lawrence and Shearer, 2006; Akaogi et al., 2007; Ye et al., 2014).

Each group is divided into 9 columns:

Column A: Average "hot" (smaller) or "cold" (larger) MTZ thickness (km) (see main text, Figure 4) estimated from all four of the mantle tomography models used to obtain receiver function peak depths (Kennett et al., 1995; Simmons et al., 2010; Brenn et al., 2017; Lloyd et al., 2019).

Column B: Assumed average MTZ thickness (km); either $250 \mathrm{~km}$ or $242 \mathrm{~km}$ (Lawrence and Shearer, 2006).

Column C: Difference (km) between the observed MTZ thickness (col. A) and the average MTZ thickness (col. B). 
Column D: Calculated change in pressure with depth (dP/dz).

Column E: Reciprocal of column D.

Column F: Assumed ringwoodite to perovskite (660') Clapeyron slope (MPa/ ${ }^{\circ} \mathrm{K}$; Akaogi et al., 2007; Ye et al., 2014; Katsura et al., 2003; or Akaogi and Ito, 1993).

Column G: Assumed wadsleyite to ringwoodite (410') Clapeyron slope (MPa/ ${ }^{\circ} \mathrm{K}$; Bina and Hellfrich, 1994).

Column H: Resulting change in MTZ temperature $\left({ }^{\circ} \mathrm{K}\right)$.

Column I: Relevant reference for the 660' Clapeyron slope and the average MTZ thickness (if value $=242 \mathrm{~km}$ ).

\section{References (Supplemental Material)}

Akaogi, M. and Ito, E., 1993, Refinement of enthalpy measurement of $\mathrm{MgSiO}_{3}$ perovskite and negative pressure-temperature slopes for perovskite-forming reactions, Geophysical Research Letters, 20(17), 1839-1842, doi: 10.1029/93GL01265

Akaogi, M., Takayama, H., Kojitani, H., Kawaji, H., and Atake, T., 2007, Low-temperature heat capacities, entropies and enthalpies of $\mathrm{Mg}_{2} \mathrm{SIO}_{4}$ polymorphs, and $\alpha-\beta-\gamma$ and post-spinel phase relations at high pressures, Physics and Chemistry of Minerals, 34(3), 169-183, doi: 10.1007/s00269-006-0137-3

An, M., Wiens, D.A., Zhao, Y., Feng, M., Nyblade, A.A., Kanao, M., Li, Y., Maggi, A. and Lévêque, 2015, S-velocity model and inferred Moho topography beneath the Antarctic Plate from Rayleigh waves: Journal of Geophysical Research Solid Earth, v. 120, doi: 10.1002/2014JB011332.

Anandakrishnan, S., Wiens, D., and Nyblade, A.A., 2000, A Broadband Seismic Investigation of Deep Continental Structure Across the East-West Antarctic Boundary. International Federation of Digital Seismograph Networks. Dataset/Seismic Network. 10.7914/SN/XP_2000

Anthony, R. E., Aster, R.C, Wiens, D., Nyblade, A., Anandakrishnan, S., Winberry, J.P., Wilson, T., and Rowe, C. (2015), The seismic noise environment of Antarctica, Seismological Research Letters, 86(1), doi:10.1785/0220140109.

Auer, L., Boschi, L., Becker, T.W., Nissan-Meyer, T., and Giardini, D., 2014, Savani: A variable resolution whole-mantle model of anisotropic shear velocity variations based on multiple data sets, Journal of Geophysical Research, 119(4), 3006-3034, doi: 10.1002/2013JB010773

Bina, C.R., 2003, 2.02 - Seismological constraints upon mantle composition, in Holland, H.D. and Turekian, K.K., eds., Treatise on Geochemistry, v. 2: Pergamon, p. 39-59, doi: 10.1016/B0-08-043751-6/02002-8

Bina, C.R. and Hellfrich, G., 1994, Phase transition Clapeyron slopes and transition zone seismic discontinuity topography, Journal of Geophysical Research, 99(B8), 15,85315,860, doi: 10.1029/94JB00462 
Brenn, G.R., Hansen, S.E., and Park, Y., 2017, Variable thermal loading and flexural uplift along the Transantarctic Mountains, Antarctica, Geology, 45(5), 463-466, doi: 10.1130/G38784.1

Chang, S.-J., Ferreira, A.M.G, Ritsema, J., van Heijst, H.J., Woodhouse, J.H., 2015, Joint inversion for global isotropic and radially anisotropic mantle structure including crustal thickness perturbations, Journal of Geophysical Research, 120(6), 4278-4300, doi: 10.1002/2014JB011824

Crotwell, H. P., Owens, T. J., and Ritsema, J., 1999, The TauP Toolkit: Flexible seismic traveltime and ray-path utilities, Seismological Research Letters 70, 154-160.

Durand, S., Debayle, E., Ricard, Y., and Lambotte, S., 2016, Seismic evidence for a change in the large-scale tomographic pattern across the D" layer, Geophysical Research Letters, 43(15), 7928-7936, doi: 10.1002/2016GL069650

Durand, S., Debayle, E., Ricard, Y., Zaroli, C., and Lambotte, S., 2017, Confirmation of a change in the global shear velocity pattern at around $1000 \mathrm{~km}$ depth, Geophysical Journal International, 211(3), 1628-1639, doi: 10.1093/gji/ggx405

Efron, B., and Tibshirani, R., 1991, Statistical data analysis in the computer age, Science, 253(5018), 390-395, doi: 10.1126/science.253.5018.390

Emry, E.L., Nyblade, A.A., Julià, J., Anandakrishnan, S., Aster, R.C., Wiens, D.A., Huerta, A.D., and Wilson, T.J., 2015, The mantle transition zone beneath West Antarctica: Seismic evidence for hydration and thermal upwellings: Geochemistry, Geophysics, Geosystems, v. 15, doi: 10.1002/2014GC005588.

French, S.W. and Romanowicz, B., 2015, Broad plumes rooted at the base of the Earth's mantle beneath major hotspots, Nature, 525, 95-99, doi: 10.1038/nature14876

Grand, S.P., 2002, Mantle shear-wave tomography and the fate of subducted slabs, Philosophical Transactions of the Royal Society of London, 360, 2475-2491, doi: 10.1098/rsta.2002.1077

Hansen, S.E., Reusch, A., Parker, T., Bloomquist, D., Carpenter, P., Graw, J.H., and Brenn, G.R., 2015, The Transantarctic Mountains Northern Network (TAMNNET): Deployment and performance of a seismic array in Antarctica, Seismological Research Letters, 86, 16361644, doi: 10.1785/0220150117

Houser, C., Masters, G., Shearer, P., and Laske, G., 2008, Shear and compressional velocity models of the mantle from cluster analysis of long-period waveforms, Geophysical Journal International, 174, 195-212, doi: 10.1111/j.1365-246X.2008.03763.x

Katsura, T., Yamada, H., Shinmei, T., Kubo, A., Ono, S., Kanzaki, M., Yoneda, A., Walter, M.J., Ito, E., Urakawa, S., Funakoshi, K., and Utsumi, W., 2003, Post-spinel transition in $\mathrm{Mg}_{2} \mathrm{SiO}_{4}$ determined by high P-T in situ X-ray diffractometry, Physics of the Earth and Planetary Interiors, 136, 11-24, doi: 10.1016/S0031-9201(03)00019-0

Kennett, B.L.N., Engdahl, E.R., and Buland, R., 1995, Constraints on seismic velocities in the earth from travel times, Geophysical Journal International, 122, 108-124, doi: 10.1111/j.1365-246X.1995.tb03540.x 
Koelemeijer, P., Ritsema, J., Deuss, A., and van Heijst, H.-J., 2016, SP12RTS: a degree-12 model of shear- and compressional-wave velocity for Earth's mantle, Geophysical Journal International, 204(2), 1024-1039, doi: 10.1093/gji/ggv481

Laske, G., Masters, G., Ma, Z., \& Pasyanos, M. (2013). Update on CRUST1.0 - A 1-degree global model of Earth's crust. Geophysical Research Abstracts, 15, Abstract EGU20132658.

Lawrence, J.F. and Shearer, P., 2006, A global study of transition zone thickness using receiver functions, J. Geophys. Research, 111, B06307, doi: 10.1029/2005JB003973

Lekic, V. and Romanowicz, B., 2011, Inferring upper-mantle structure by full waveform tomography with the spectral element method, Geophysical Journal International, 185(2), 799-831, doi: 10.1111/j.1365-246X.2011.04969.x

Ligorría, J.P., and Ammon, C.J., 1999, Iterative deconvolution and receiver-function estimation, Bulletin of the Seismological Society of America, 89(5), 1395-1400,

Lloyd, A.J., Wiens, D.A., Zhu, H., Tromp, J., Nyblade, A.A., Aster, R.C., Hansen, S.E., Dalziel, I.W.D., Wilson, T.J., Ivins, E.R., and O'Donnell, J.P., 2019, Seismic Structure of the Antarctic Upper Mantle Based on Adjoint Tomography, Journal of Geophysical Research.

Lu, C. and Grand, S.P., 2016, The effect of subducting slabs in global shear wave tomography, Geophysical Journal International, 205(2), 1074-1085, doi: 10.1093/gji/ggw072

Montelli, R., Nolet, G., Dahlen, F.A., and Master, G., 2006, A catalogue of deep mantle plumes: New results from finite-frequency tomography, Geochemistry, Geophysics, Geosystems, 7(11), Q11007, doi: 10.1029/2006GC001248

Moulik, P. and Ekström, G., 2014, An anisotropic shear velocity model of the Earth's mantle using normal modes, body waves, surface waves and long-period waveforms, Geophysical Journal International, 199(3), 1713-1738, doi: 10.1093/gji/ggu356

Owens, T.J., Crotwell, H.P., Groves, C., and Oliver-Paul, P., 2004, SOD: Standing order for data, Seismological Research Letters, 75(4), 515-520.

Owens, T.J., Nyblade, A.A., Gurrola, H., and Langston, C.A., 2000, Mantle transition zone structure beneath Tanzania, East Africa: Geophysical Research Letters, v. 27, no. 6, p. 827-830, doi: 10.1029/1999GL005429.

Panning, M.P., Lekić, V., and Romanowicz, B.A., 2010, Importance of crustal corrections in the development of a new global model of radial anisotropy, Journal of Geophysical Research, 115(B12), 10.1029/2010JB007520

Ritsema, J., van Heijst, H.J., and Woodhouse, J.H., 1999, Complex shear wave velocity structure imaged beneath Africa and Iceland, Science, 286(5446), 1925-1928, doi: 10.1126/science.286.5446.1925

Ritsema, J., Deuss, A., van Heijst, H.J., and Woodhouse, J.H., 2011, S40RTS: a degree-40 shear-velocity model for the mantle from new Rayleigh wave dispersion, teleseismic traveltime and normal-mode splitting function measurements, Geophysical Journal International, 184, 1223-1236, doi: 10.1111/j.1365-246X.2010.04884.X 
Schaeffer, A.J. and Lebedev, S., 2013, Global shear speed structure of the upper mantle and transition zone, Geophysical Journal International, 194, 417-449, doi: 10.1093/gji/ggt095

Simmons, N.A., Forte, A.M., Boschi, L., and Grand, S.P., 2010, GyPSuM: A joint tomographic model of mantle density and seismic wave speeds: Journal of Geophysical Research, v. 115, no. B12310, doi: 10.1029/2010JB007631

Tesoniero, A., Auer, L., Boschi, L., and Cammarano, F., 2015, Hydration of marginal basins and compositional variations within the continental lithospheric mantle inferred from a new global model of shear and compressional velocity, Journal of Geophysical Research: Solid Earth, 120(11), 7789-7813, doi: 10.1002/2015JB012026

Wiens, D. and Nyblade, A., 2007, A Broadband Seismic Experiment to Image the Lithosphere beneath the Gamburtsev Mountains, East Antarctica. International Federation of Digital Seismograph Networks. Dataset/Seismic Network. 10.7914/SN/ZM_2007

Wiens, D., Nyblade, A., and Aster, R., 2007, IPY POLENET-Antarctica: Investigating links between geodynamics and ice sheets. International Federation of Digital Seismograph Networks. Dataset/Seismic Network. 10.7914/SN/YT_2007

Zhao, D., Hasegawa, A., and Kanamori, H., 1994, Deep structure of Japan subduction zone as derived from local, regional, and teleseismic events, Journal of Geophysical Research: Solid Earth, 99(11), 22,313-22,329, doi: 10.1029/94JB01149 